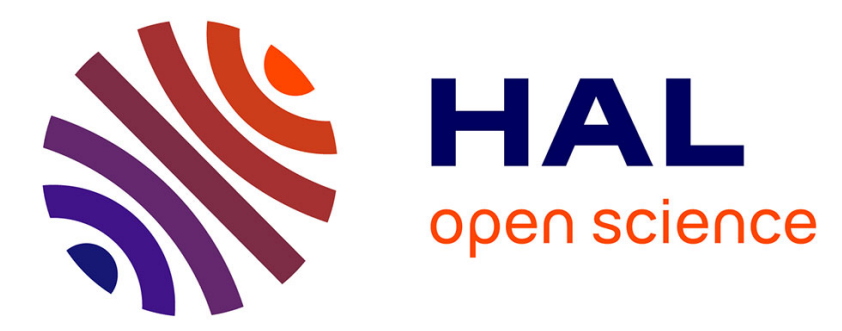

\title{
Potential benefits of genomic selection on genetic gain of small ruminant breeding programs
}

\author{
Félicien Shumbusho, Jérôme Raoul, Jean-Michel Astruc, Isabelle Palhiere \\ Palhière, Jean Michel J. M. Elsen
}

\section{> To cite this version:}

Félicien Shumbusho, Jérôme Raoul, Jean-Michel Astruc, Isabelle Palhiere Palhière, Jean Michel J. M. Elsen. Potential benefits of genomic selection on genetic gain of small ruminant breeding programs. Journal of Animal Science, 2013, 91 (8), pp.3644 - 3657. 10.2527/jas.2012-6205 . hal-02646766

\section{HAL Id: hal-02646766 \\ https://hal.inrae.fr/hal-02646766}

Submitted on 29 May 2020

HAL is a multi-disciplinary open access archive for the deposit and dissemination of scientific research documents, whether they are published or not. The documents may come from teaching and research institutions in France or abroad, or from public or private research centers.
L'archive ouverte pluridisciplinaire HAL, est destinée au dépôt et à la diffusion de documents scientifiques de niveau recherche, publiés ou non, émanant des établissements d'enseignement et de recherche français ou étrangers, des laboratoires publics ou privés. 


\title{
Potential benefits of genomic selection on genetic gain of small ruminant breeding programs ${ }^{1}$
}

\author{
F. Shumbusho, ${ }^{*} \dagger^{2}$ J. Raoul, $*$ J. M. Astruc, $*$ I. Palhiere, $\dagger$ and J. M. Elsen $\dagger^{2}$ \\ *Institut de l'Elevage, F-31321 Castanet-Tolosan, France; and †INRA, UR631 SAGA, F-31326 Castanet-Tolosan, France
}

\begin{abstract}
In conventional small ruminant breeding programs, only pedigree and phenotype records are used to make selection decisions but prospects of including genomic information are now under consideration. The objective of this study was to assess the potential benefits of genomic selection on the genetic gain in French sheep and goat breeding designs of today. Traditional and genomic scenarios were modeled with deterministic methods for 3 breeding programs. The models included decisional variables related to male selection candidates, progeny testing capacity, and economic weights that were optimized to maximize annual genetic gain (AGG) of i) a meat sheep breeding program that improved a meat trait of heritability $\left(h^{2}\right)=0.30$ and a maternal trait of $h^{2}=0.09$ and ii) dairy sheep and goat breeding programs that improved a milk trait of $h^{2}=$ 0.30 . Values of \pm 0.20 of genetic correlation between meat and maternal traits were considered to study their effects on AGG. The Bulmer effect was accounted for and the results presented here are the averages of AGG after 10 generations of selection. Results showed that current traditional breeding programs provide an AGG of 0.095 genetic standard deviation $\left(\sigma_{a}\right)$ for meat and
\end{abstract}

$0.061 \sigma_{a}$ for maternal trait in meat breed and $0.147 \sigma_{a}$ and $0.120 \sigma_{a}$ in sheep and goat dairy breeds, respectively. By optimizing decisional variables, the AGG with traditional selection methods increased to $0.139 \sigma_{a}$ for meat and $0.096 \sigma_{a}$ for maternal traits in meat breeding programs and to $0.174 \sigma_{a}$ and $0.183 \sigma_{a}$ in dairy sheep and goat breeding programs, respectively. With a medium-sized reference population (nref) of 2,000 individuals, the best genomic scenarios gave an AGG that was $17.9 \%$ greater than with traditional selection methods with optimized values of decisional variables for combined meat and maternal traits in meat sheep, $51.7 \%$ in dairy sheep, and $26.2 \%$ in dairy goats. The superiority of genomic schemes increased with the size of the reference population and genomic selection gave the best results when nref $>1,000$ individuals for dairy breeds and nref $>2,000$ individuals for meat breed. Genetic correlation between meat and maternal traits had a large impact on the genetic gain of both traits. Changes in AGG due to correlation were greatest for low heritable maternal traits. As a general rule, AGG was increased both by optimizing selection designs and including genomic information.

Key words: breeding programs, deterministic simulation, genetic gain, genomic selection, small ruminants

(C) 2013 American Society of Animal Science. All rights reserved.

J. Anim. Sci. 2013.91:3644-3657 doi:10.2527/jas2012-6205

\section{INTRODUCTION}

Genomic evaluation (Meuwissen et al., 2001) is largely being adopted in dairy cattle breeding programs (e.g., Hayes et al., 2009; Lund et al., 2011; Boichard et

\footnotetext{
${ }^{1}$ This study is part of the CASDAR GENOVICAP project funded by the French Ministry of Agriculture. We gratefully acknowledge the funding. We also thank anonymous reviewers for valuable comments and suggestions.

${ }^{2}$ Corresponding author: felicien.shumbusho@toulouse.inra.fr; Jean-Michel.Elsen@toulouse.inra.fr

Received December 21, 2012.

Accepted April 30, 2013.
}

al., 2012). By including genomic information, genomic breeding values (GBV) can be estimated accurately without having to phenotype the candidates. This means that it is now possible to select for traits that are expensive or difficult to measure, to select candidates early in life, to select females on male traits and vice versa, and ultimately to increase the annual genetic gain (AGG). Simulation studies reported greater AGG with genomic selection (GS) compared with traditional selection in dairy cattle (e.g., Schaeffer, 2006; Konig and Swalve, 2009), beef cattle (Pimentel and Konig, 2012), and horses (Haberland et al., 2012). Studies using genomic information for the genetic evaluation 
of small ruminants are emerging (Daetwyler et al., 2012; Duchemin et al., 2012) and, to our knowledge, there is no published work on the impacts of GS on the genetic gain of small ruminant breeding programs. In these species, specific factors could limit the AGG obtained from GS, mainly because of the lack of enough reliable phenotypes to accurately predict GBV, the relatively short generation interval, and the high genotyping cost per animal. However, with developments in genomics and the possible reduction of genotyping costs, GS could also be profitable in sheep and goat selection programs in the near future.

The aim of this study was to model, optimize, and compare the AGG of genomic and conventional selection scenarios relevant to 3 real small ruminant breeding programs. A medium-sized reference population of individual animals was assumed for the GS schemes of each breed. Factors that might affect the accuracy of genomic prediction were not studied, but the deterministic formulas described by Daetwyler et al. (2008) and Goddard (2009) were used instead.

\section{MATERIALS AND METHODS}

Animal Care and Use Committee approval was not obtained for this study as no animals were used.

In this study, breeding programs currently used for meat and dairy small ruminants were modeled considering their designs and functionalities to assess alternative, optimized, traditional, and genomic scenarios.

\section{Breeding Schemes}

The different elements of small ruminant breeding programs are represented in Fig. 1a. This breeding scheme is based on the selection scheme used for the Mouton Ile de France breed, a meat sheep breeding program that consists of multiple stages of selection and uses different sources of information. In a first selection stage lambs are selected on average EBV of meat and maternal traits of their parents, a second stage consists of selecting young rams on their meat records, and, in a final stage, rams are selected based on the meat and maternal records of their progeny. Figure $1 b$ shows a more simplified breeding scheme corresponding to other small ruminant breeding programs, such as those used for dairy sheep and dairy goats. This simple scheme is based on the programs currently used for dairy breeds such as the Red Faced Manech (RFM) sheep and the Alpine goat. In these selection plans, males are at first selected on the average EBV of their parents and then selected again after progeny testing. In all breeding programs, females are first selected based on the average (a)

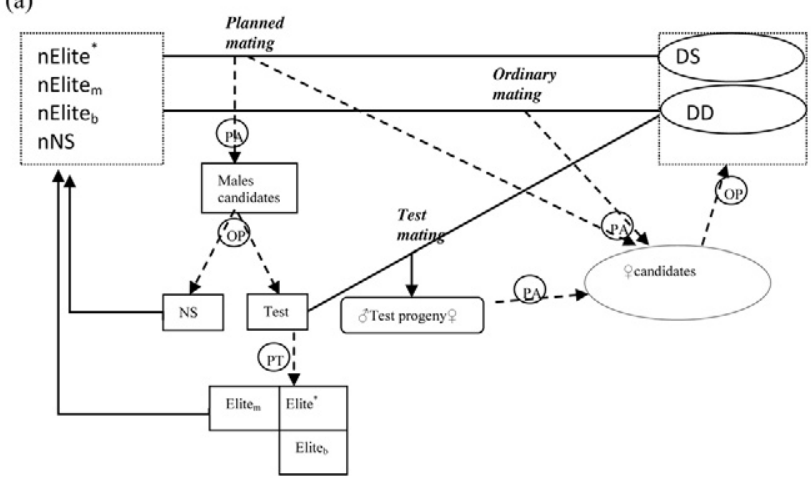

(b)

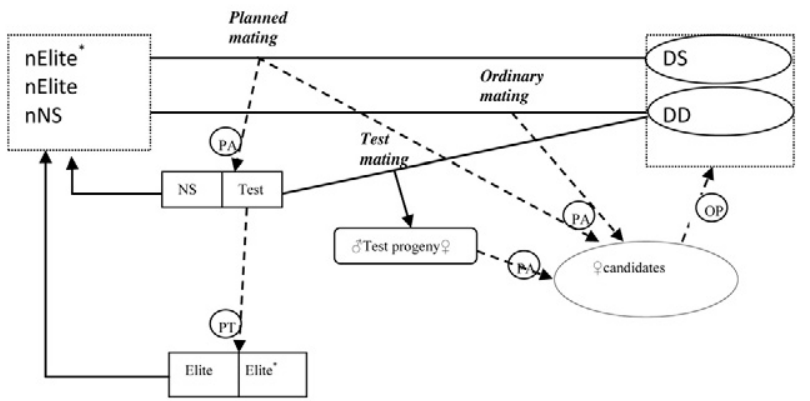

Figure 1. Population structure and selection steps of the studied breeding schemes. Full lines indicate mating paths and dotted arrows indicate selection based on parent averages (PA), own performance (OP), and progeny testing (PT). Male selected categories for the meat breeding program (a) are natural service (NS) males, test males (Test), and proven males; Elite ${ }_{b}$, Elite ${ }_{m}$, and Elite* to refer to best animals for meat, maternal, and both traits, respectively. Selected categories for the dairy breeding programs (b) are NS males, Test, and proven males; Elite* and Elite to refer to first and second categories on genetic level. Female selected categories are dams of sires (DS) and dams of dams (DD) for all breeding programs. These candidates are selected each year to renew a proportion of the corresponding total male and female reproducers in breeding unit (i.e., $\mathrm{nNS}$, Test, $\mathrm{nElite}_{\mathrm{b}}$, nElite $_{\mathrm{m}}$, and $\mathrm{nElite}^{*}$ males for the meat breeding program; nNS, Test, nElite, and nElite* males for the dairy breeding programs and DS and DD females for each breeding program).

EBV of their parents and, in a second phase, on their phenotypes. Technical documents for the concerned breeding schemes are available on request.

\section{Breeding Schemes Scenarios}

To assess the potential impacts of GS and optimization in current sheep and goats breeding programs, we modeled, optimized, and compared 9 scenarios for the meat sheep breeding program and 3 scenarios for each of the dairy sheep and goat breeding programs, with or without genomic information. All scenarios are listed in Table 1 and described hereafter. Table 1 also gives corresponding sources of information on male selection candidates and types of selection for each scenario. For all scenarios, young males and females were considered selection candidates based on the breeding values of their parents (i.e., average EBV of parents) of corresponding traits (i.e., 
Table 1. Summary of breeding schemes simulated scenarios

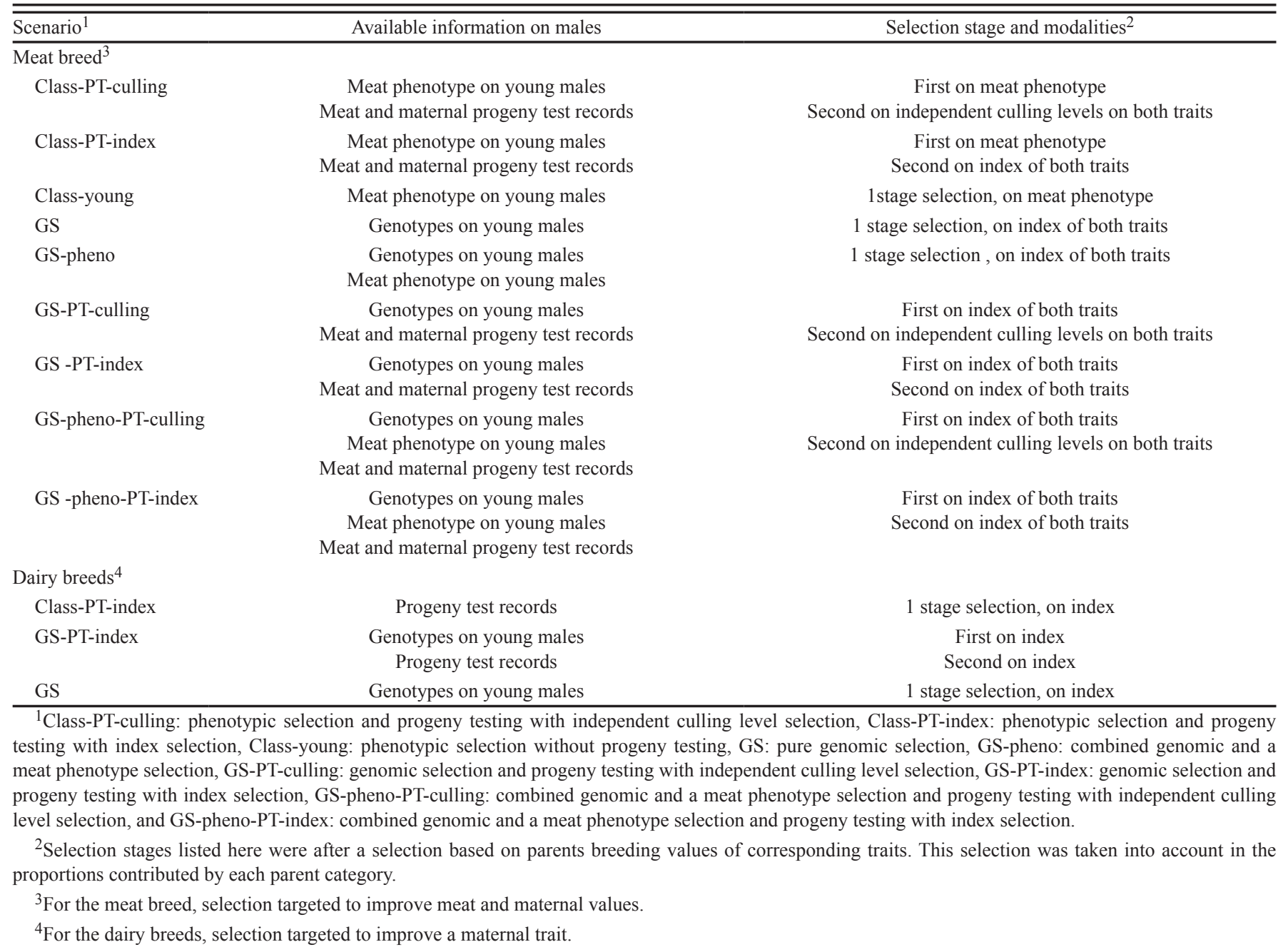

meat and maternal traits for meat sheep breeding program and maternal trait for dairy breeding programs).

\section{Meat Breeding Program: Two-Trait Selection}

Selection was performed for meat and maternal traits.

Scenario Class-PT-Culling. This scenario reflects the conventional breeding program. Therefore, after selection on average EBV of meat and maternal traits of parents, young males were selected based on their meat records and the final selection step performed with independent culling methods on both meat and maternal records of the progeny. This method is commonly used in French meat breeding programs involving selection on meat and maternal traits because data for the meat trait are recorded at an earlier stage for the progeny. Indeed, when trait records become available at different ages or when there are differences in the costs of records, then use of independent culling levels may give greater aggregate economic return than index selection (Ducrocq and Colleau, 1989). This scenario was used as a reference for the meat breeding program.
Scenario Class-PT-Index. This scenario used the same sources of information as Class-PT-culling, but the selection step after progeny testing was performed using an index combining progeny records for both meat and maternal traits to form a single selection criterion. This scenario was used to study the effect of adopting a combined selection index in current breeding programs.

Scenario Class-Young. The scenario assumes the conventional breeding program without progeny testing. After a selection on average EBV of parents for both traits, young males were selected based on their meat value. Among the selected males, the top best were qualified as elite males and used for AI mating; the others were qualified as natural service (NS) males. This scenario was used to study the effect of lowering generation interval and selection accuracy.

Genomic Selection. This was a pure genomic selection scenario. Young male selection candidates were genotyped and best reproducers selected on their GBV of meat and maternal traits at an early age. This scenario was similar to the "turbo scheme" proposed for use in dairy 
cattle (Buch et al., 2012) to quantify the effect of reducing the generation interval and use of genomic information.

Scenario GS-Pheno. Young male selection candidates were genotyped and phenotyped for the meat trait. Indeed, in meat sheep breeding programs a meat phenotype can be recorded before reproduction age. This scenario is therefore similar to the GS scenario with an additional meat phenotype. This scenario was aimed at assessing the usefulness of the genomic selection strategy for both traits when a meat phenotype is available from an early age.

Scenario GS-PT-Culling. This scenario consisted of 2 stages of selection and included GS as a preselection step. Young males were genotyped and selected on their GBV for progeny testing (as for the GS scenario). Then, independent culling level methods were used to select proven rams (elites) based on progeny test results.

Scenario GS-PT-Index. This scenario also used the GS scenario procedures as a preselection step. After progeny testing, elite rams were selected using a single index that combined meat and maternal records of their progeny.

Scenario GS-pheno-PT-Culling. Combined GBV of both traits and a meat phenotype were used to preselect rams (GS-pheno scenario) for progeny testing. After progeny testing, elite rams were selected by independent culling levels for both trait values. This scenario is similar to GS-PT-culling with an additional meat phenotype in the preselection step and to ClassPT-culling with additional genomic information in the preselection step.

Scenario GS-pheno-PT-Index. This scenario used same sources of information as GS-pheno-PT-culling, but elite rams were selected using index that combine meat and maternal progeny records.

For all scenarios that included genomic information, the number of genotyped males was either equal to the current number of male selection candidates (i.e., 300 individuals as given in Table 2) or optimized with a maximum limit of 500 individuals.

\section{Dairy Breeding Programs: Single-Trait Selection}

Conventional breeding programs for RFM dairy sheep and Alpine dairy goat breeds were modeled, optimized, and compared with alternative genomic breeding programs.

Scenario Class-PT-Index. For each breed, this scenario was the reference and models the design and functionalities of the schemes currently in use. After the selection on average EBV of maternal trait of parents, males are progeny tested and elite males selected on maternal values of their progeny.
Scenario GS-PT-Index. In this scenario genomic information was used to preselect candidates for progeny testing. After a selection on average EBV of a maternal trait of parents, males were genotyped and selected on their GBV for progeny testing. Elite males were then selected based on maternal values of their daughters. This scenario was similar to Class-PT-index in terms of generation interval.

Genomic Selection. This was a pure genomic scheme. After the selection on average EBV of maternal trait of parents, males were genotyped and selected on the basis of their GBV. Progeny testing was avoided.

In all genomic scenarios, it was assumed that 500 male Alpine goat and 1,000 RFM sheep selection candidates were genotyped per year. These numbers were set in an effort to remain close to the current availability of male selection candidates and capacity of each breeding program.

\section{Parameter Assumptions}

Population parameters and variables used in the model are provided in Table 2. Equations describing relationships among parameters, decision variables, and internal variables of the model and constraints on internal variables are also given in Appendix 1. These equations describe different elements of the selection process. For meat breeding programs, the genetic response was predicted for 2 traits: i) a maternal trait (prolificacy) of heritability $\left(\boldsymbol{h}^{\mathbf{2}}\right)=0.09$ and repeatability (rep) $=0.12$ and ii) a meat trait (ADG) of $h^{2}=0.30$. Three levels of genetic correlations $\left(\boldsymbol{\rho}_{\boldsymbol{m b}}\right)$ between the 2 traits were examined: $\rho_{m b}=0.20,0.00$, or -0.20 . In the real practice of this meat breeding program it is considered there is no correlation between meat and maternal traits. However, small genetic correlations between litter size and weaning weight in Merino sheep have been reported (Safari et al., 2007). So in this study we wanted to explore possible effects that small values of genetic correlation can have on AGG. To reduce the number of combinations, the phenotypic correlation was set equal to the genetic correlation. In dairy breeding programs, a milk trait of $h^{2}=0.30$ and rep $=0.50$ was studied. Decisional variables were optimized for fair comparisons between the various alternative schemes, but also, results are provided with AI limited to its current level of use in breeding units. Indeed, the use of AI in breeding programs for small ruminants is still limited by many factors, such as its cost and use of fresh semen in sheep. Because any optimal AI-related parameters described in this study might not easily be adopted in practice, we also compared scenarios where other decisional variables were optimized but AI restricted. 
Table 2. Parameters of the breeding programs studied

\begin{tabular}{|c|c|c|c|c|}
\hline \multirow[b]{2}{*}{ Parameter } & \multirow[b]{2}{*}{ Name } & \multicolumn{3}{|c|}{ Value } \\
\hline & & Mouton Ile de France & $\mathrm{RFM}^{1}$ & Alpine \\
\hline \multicolumn{5}{|l|}{ Demographic } \\
\hline Percent of females qualified to be dams of male replacements & $\mathrm{pF}$ & $70 \%$ & $70 \%$ & $50 \%$ \\
\hline Age of females when first progeny are born & ageF & 2.5 & 2.5 & 2.5 \\
\hline Age of proven sires when first progeny are born & ageAI & 3.5 & 3.0 & 3.0 \\
\hline Time units males are kept in service & $\mathrm{tm}$ & 3 & 3 & 3 \\
\hline Time units females are kept in service & $\mathrm{tf}$ & 6 & 4 & 4 \\
\hline Maximum number of AI doses per proven sire in breeding unit & $\mathrm{AI}_{\max }$ & 350 & 350 & 700 \\
\hline Effective population size & $\mathrm{Ne}$ & 200 & 200 & 200 \\
\hline Base reference population size & nref & 2,000 & 2,000 & 2,000 \\
\hline Stayability of males & surM & 0.8 & 0.8 & 0.8 \\
\hline Fertility with AI & ferAI & 0.6 & 0.6 & 0.6 \\
\hline Fertility with NS & ferNS & 0.9 & 0.9 & 0.9 \\
\hline Prolificacy & pr & 1.4 & 1.4 & 1.8 \\
\hline Sex ratio & $\mathrm{sr}$ & 0.5 & 0.5 & 0.5 \\
\hline \multicolumn{5}{|l|}{ Genetic } \\
\hline Heritability of meat trait & $h^{2}$ & 0.3 & - & - \\
\hline Heritability of maternal trait & $h^{2}$ & 0.09 & 0.3 & 0.3 \\
\hline Repeatability of maternal trait & rep & 0.12 & 0.5 & 0.5 \\
\hline Genetic SD & $\sigma_{a}$ & 1 & 1 & 1 \\
\hline Correlation between the 2 traits & $\rho_{m b}$ & 0.2 or 0.0 or -0.2 & - & - \\
\hline Economic weights between traits & $w$ & 0.5 & - & - \\
\hline \multicolumn{5}{|l|}{${ }^{1}$ RFM = Red Faced Manech. } \\
\hline \multicolumn{5}{|c|}{${ }^{2} \mathrm{NS}=$ Natural Service. } \\
\hline \multicolumn{5}{|c|}{${ }^{3}$ The number of genotyped males of Mouton Ile de France breed was always equal to male selection candidates (Ms). } \\
\hline \multicolumn{5}{|c|}{${ }^{4}$ Decisional variables were optimized to guarantee a fair comparison of alternative selection scenarios. } \\
\hline
\end{tabular}

\section{Genetic Selection Model}

Deterministic methods were used to describe selection and predict genetic response. Selected males and females were divided into groups based on their sex $s(s=1$ for males and $s=2$ for females), category $j$ ( 3 to 5 categories for males, depending on selection schemes scenario and 2 categories for females) of different genetic levels, and age class $l$ (up to 3 classes for males and up to 4 or 6 for females, depending on breeds) at selection. Each year, different male categories were qualified depending on the selection modalities adopted. For scenarios in which selection was carried out using independent culling methods, 5 male categories were considered: Elite*,
Elite $_{\boldsymbol{m}}$, and Elite $_{\boldsymbol{b}}$ (to refer to the best males on both traits, maternal traits, and meat traits, respectively), Test (males in progeny testing), and NS (natural service males, which are the last category in genetic level), as shown in Fig. 1a. When selection after progeny testing was index based, Elite* and Elite (respectively, to refer to the first and second category on genetic level basis), Test (males in progeny testing), and NS (natural service males) parent groups were qualified after selection (Fig. 1b). In scenarios without progeny testing, only 3 categories were included (Elite*, Elite, and NS) after each selection cycle. Females were divided into dams of sires (DS) and dams of dams (DD; to refer to first and second categories in genetic 
level, respectively). These subdivisions were considered to reflect the genetic heterogeneity currently observed for reproducers in breeding units. To emulate current practice, males were selected considering a single selection cycle per generation whereas females were reclassified every year on the basis of their EBV, a unique truncation point being used across a multiple normal distribution of female genetic levels for different age classes.

The genetic superiority of a selected male category at each selection stage was calculated as

$$
\mu_{1 j l}=i_{1 j l} r_{I H_{1 j l}} \sigma_{a},
$$

in which $i_{1 j l}$ is the selection intensity, $r_{I H_{1 j l}}$ is the correlation between index $(\boldsymbol{I})$ and breeding goal $(\boldsymbol{H})$ for the selection of males belonging to category $j$ and age class $l$, and $\sigma_{a}$ is the standard deviation of the breeding values. Within a given category, all males were assumed to have the same age at selection. Therefore, $l$ was always 1 for selected males.

\section{Selection Intensity}

Selection intensities were obtained for males after each selection stage via integration of a truncated univariate (for single trait or index) standard normal distribution:

$$
\begin{aligned}
& i_{1 j}=\left[\exp \left(-0.5 T_{1 j}^{2}\right) /(2 \pi)^{1 / 2}\right] /\left(1 / q_{1 j}\right), \text { with } \\
& q_{1 j}=\int_{T_{1 j}}^{\infty}\left[1 /(2 \pi)^{1 / 2}\right] e^{-0.5 x^{2}} d x,
\end{aligned}
$$

in which $T_{1 j}$ is the single trait or index threshold above which category $j$ males were kept. For 2-trait independent culling selection, a standard bivariate normal distribution (SBN) was used:

$$
\begin{aligned}
& i_{1 j}=\left(\int_{T_{m 1 j}}^{\infty} \int_{T_{b 1 j}}^{\infty} \operatorname{SBN}\left(x, y, \rho_{b m}\right) d x d y\right) / q_{1 j}, \text { with } \\
& q_{1 j}=\int_{T_{m 1 j}}^{\infty} \int_{T_{b 1 j}}^{\infty} f(x, y) d x d y,
\end{aligned}
$$

in which $T_{b 1 j}$ and $T_{m 1 j}$ are truncation points of the joint distribution of meat $(b)$ and maternal $(m)$ genetic values, $q_{1 j}$ is the proportion selected, and $\rho_{b m}$ is the correlation between meat and maternal traits. Functions C05ADF and D01AMF of the NAG (Numerical Algorithms Group Ltd., Oxford, UK) library were used for accurate numerical integration of normal distributions. The selection intensity of any subsequent selection events was calculated based on the proportion selected at that stage and taking into account the reduction in genetic variance due to previous selection steps.

Females were evaluated on their own phenotypes and selected after the optimal rule selection scheme proposed by Bichard et al. (1973) and Elsen and Mocquot (1976).
With this method, animals are selected with a unique truncation point across multinormal distributions of their breeding values. This method maximizes the genetic superiority of selected parents, considering that animals of younger age classes are genetically superior to older animals but known with a lower precision. The average superiority of each female category (i.e., DS or DD) was calculated as

$$
\mu_{2 j l}=\sum_{l} \gamma_{2 j l} i_{2 j l} r_{I H_{2 j l}} \sigma_{2 j l}
$$

in which the summation includes all age classes $l, \gamma_{2 j l}$ is the contribution of age class $l, i_{2 j l}$ and $r_{I H_{2 i l}}$ are the selection intensity and accuracy for the selection of females of category $j$ and age class $l$, and $\sigma_{2 j l}$ is the genetic standard deviation of the corresponding female category, corrected for genetic reduction due to previous selection on age class.

\section{Selection Accuracy}

The correlation between $I$ and $H\left(r_{I H}\right)$ was calculated using selection index methods including either phenotypic or genomic information or both. The methodology described by Dekkers (2007) that combines phenotypic and genomic information via selection index theory was used. With this method, genomic information is included as a trait with a heritability of 1 (i.e., the repeatability of SNP information) and genetic correlation to the selection criterion is determined by its prediction accuracy $\left(r_{\mathrm{GBV}}\right)$. Genomic prediction accuracies were calculated using the formula described by Daetwyler et al., (2008).

$$
r_{\mathrm{GBV}}=\left\{\text { nref } \times\left[h^{2} /\left(\text { nref } \times h^{2}+\mathrm{Me}\right)\right]\right\}^{1 / 2},
$$

in which $\mathrm{Me}=2 \mathrm{Ne} L / \log (4 \mathrm{Ne} L)$ is the number of effective genome segments (Goddard, 2009), which depends on the effective population size of the considered population $(\mathrm{Ne})$ and the genome length in morgans $(L)$, nref is the number of animals forming the reference population, and $h^{2}$ is the heritability of the trait. The use of $h^{2}$ in the above formula means that genotyped animals in the reference population also had their own phenotypes.

The breeding goal was $H=\left(\mathrm{BV}_{b}, \mathrm{BV}_{m}\right) \mathbf{w}$ when applying an index selection on 2 traits, in which $\mathrm{BV}_{b}$ and $\mathrm{BV}_{m}$ are the breeding values of meat and maternal traits, respectively, and $\mathbf{w}$ is a vector of weights. It must be emphasized that these weights were not the economic weights classically defined in the selection index theory but technical weights to be optimized to maximize the overall (on 2 traits) genetic progress created by the selection scheme. Indeed, in this situation with 2 traits, the objective function was a linear combination of the genetic progress of both traits weighted by economic weights 
$(\alpha)$. This objective function depended on a number of decisional variables to be optimized to give a maximum overall genetic gain. Depending on the selection scheme and available information sources (Table 1), the index, $l$, included genomic values, phenotypes, or both sources of information for male selection candidates. Females were evaluated on their own repeated phenotypes.

Following standard selection index procedures, genetic and genomic parameters for individual selection candidates or their progeny were used to set up matrices $\mathbf{P}, \mathbf{G}$, and $\mathbf{C}$. Matrix $\mathbf{P}$ was the variances and covariances matrix between all components of the selection index for the given scenario (e.g., $I=\left(\mathrm{P}_{b}, \mathrm{GBV}_{b}, \mathrm{GBV}_{m}\right) b$ for the GS-pheno scenario), $\mathbf{G}$ was the matrix of variances and covariances between these components of the selection index and the additive genetic values for the traits in the breeding goal, and matrix $\mathbf{C}$ contained genetic variances and covariances between all traits in the breeding goal. When the type of information in the index was only phenotypes, elements of $\mathbf{P}$ and $\mathbf{G}$ were calculated as a function of phenotypic and genetic parameters of the traits, as described by Hazel (1943). When information sources in the index included GBV, elements of $\mathbf{P}$ and $\mathbf{G}$ matrices were computed as described by Dekkers (2007). Then, the vector $\mathbf{b}$ of index coefficients, the variance of the breeding goal, $\sigma_{H}^{2}=w^{\prime} C w$, the variance of the index, $\sigma_{I}^{2}=b^{\prime} G w$, and the selection accuracy of each trait, $r_{I, \mathrm{BV}}$ $=\operatorname{cov}\left(\mathrm{BV}, I / \sigma_{\mathrm{BV}} \sigma_{I}\right)$, were calculated for each scenario.

The AGG of all 4 selection paths $p$ (MM, MF, FM, and $\mathbf{F F}$ for males to males, males to females, females to males, and females to females, respectively) for each trait was then calculated as

$$
\mathrm{AGG}=\Sigma_{p} \Sigma_{j} c_{s j l p} \mu_{s j l} / \Sigma_{p} \Sigma_{j} c_{s j l p} L_{s j l}
$$

in which summations included selection paths $p$ and selected category $j, c_{s j l p}$ is the fraction contributed by animal category $j$ of $\operatorname{sex} s$ and age class $l$ to selection path $p$, and $\mu_{s j l}$ and $L_{s j l}$ are corresponding genetic superiority and average age, respectively.

\section{Accounting for Variance Reduction}

Selection reduces genetic variance and thus reduces genetic gain in subsequent generations due to the "Bulmer effect" (Bulmer, 1971). To account for this variance reduction and consequences on genetic response, the AGG was predicted, as proposed by Pryce et al., (2010), by averaging the genetic response over 10 generations corrected for variance reduction after each cycle of selection. In generation $t$, the variance of a selected category $(s j l)$ was calculated as

$$
\sigma_{s j l, t}^{2^{*}}=\sigma_{s j l, t}^{2}\left(1-r_{I H_{j l}}^{2} K\right)
$$

in which $\sigma_{s j l, t}^{2}$ is the genetic variance before selection and $\sigma_{s i l, t}^{2^{*}}$ after selection of group $s j l$ in generation $t, r_{I H_{j l}}^{2}$ is the selection accuracy, and $K$ is a variance reduction factor. The above formula of Bulmer (1971) was extended to the different selection modalities used in the breeding programs studied here. Because candidate groups within each sex have different genetic levels, the variance of selected parents contributing to each selection path $(p)$ was calculated accounting for the variability of both means and variances of categories contributing to the corresponding path:

$$
\sigma_{p, t}^{2^{*}}=\sum_{j l} c_{s j l p} \sigma_{s j l, t}^{2^{*}}+\sum_{j l} c_{s j l} \mu_{s j l}^{2}-\left(\sum_{j l} c_{s j l} \mu_{s j l}\right)^{2},
$$

in which summation is over selected category $j$ and age $l$ contributing to $p$ th selection path, $\sigma_{p, t}^{2^{*}}$ is the variance of selected parents of $p$ th path, $c_{s j l p}$ is the contribution of category sjl to that $p$ th selection path, and $\sigma_{s j l, t}^{2 *}$ and $\mu_{s j l}$ are, as defined previously, the variance and genetic superiority of the selected group $s j l$, in generation $t$, respectively. Hence, the genetic variances in newborns of the subsequent generation are the assembled genetic variances of selected parents and Mendelian-sampling variance:

$$
\begin{aligned}
& \sigma_{1, t+1}^{2}=\left[\left(\sigma_{M M, t}^{2^{*}}+\sigma_{F M, t}^{2^{*}}\right) / 4\right]+\left(\sigma_{a}^{2} / 2\right) \text { and } \\
& \sigma_{2, t+1}^{2}=\left[\left(\sigma_{M F, t}^{2^{*}}+\sigma_{F F, t}^{2^{*}}\right) / 4\right]+\left(\sigma_{a}^{2} / 2\right),
\end{aligned}
$$

in which $\sigma_{1, t+1}^{2}$ and $\sigma_{2, t+1}^{2}$ are the variances of male and female progenies, respectively, and $\sigma_{a}^{2} / 2$ is the Mendelian-sampling variance, which is estimated to be equal to one-half of the genetic variance of the unselected population.

\section{Optimization}

The objective function to be maximized was the total genetic gain for a considered selection criterion. It was laid out as

$$
\begin{array}{r}
\text { Maximizing } \operatorname{AGG}_{\text {tot }}(x)=\alpha_{b} \cdot \operatorname{AGGb}(x)+ \\
\alpha_{m} \cdot \operatorname{AGGm}(x) \text {, subject to } x_{l} \leq x \leq x_{u} \text { constraints }
\end{array}
$$

in which $x$ is a vector of decision variables (initial values given in Table 2), $x_{l}$ and $x_{u}$ are the lower and upper limits of constraints, respectively, and $\alpha_{b}$ and $\alpha_{m}$ are the weights given to the genetic progress of meat and maternal traits, respectively, in the overall genetic gain. $\mathrm{AGG}_{\text {tot }}$ is the total annual genetic gain, and AGGb and AGGm are the annual genetic gains for the meat and maternal traits, respectively. Vector $\left[\alpha_{b}, \alpha_{m}\right]$ was first given values $[1$, 1] and then varied to assess the stability of the function in different scenarios. In single-trait situations, such 
as found in dairy breeds, $\mathrm{AGG}_{\mathrm{tot}}(x)=\mathrm{AGG}(x)$ without $\alpha$ weight. The E05JBF subroutine of the NAG library was used to maximize the above function. It is designed to find a global minimum or maximum of an arbitrary function, subject to simple bound constraints using a multilevel coordinate search method.

\section{RESULTS}

\section{Predicted Genetic Gain in Current and Optimized Schemes}

The expected AGG in current and optimized conventional and genomic breeding programs is given in Table 3 for meat breed and in Table 4 for dairy breeds. All results presented in this paper are the averages of 10 generations of selection taking into account the Bulmer effects on genetic progress. In the GS scenarios, a medium-sized reference population (nref $=2,000$ ) of genotyped and phenotyped individuals and $\mathrm{Ne}=200$ were used to calculate the $r_{\mathrm{GBV}}$. A fair comparison of GS and classic selection scenarios must be based on same optimal conditions. As the current use of decisional variables of the studied breeding programs may not be optimal, comparisons were performed with currently used and optimized decisional variables.

\section{Meat Breeding Program}

In its current form, the breeding program for the meat breed "Mouton Ile de France" is expected to give an annual genetic gain of 0.095 genetic standard deviation $\left(\sigma_{a}\right)$ for the meat trait and $0.061 \sigma_{a}$ for the maternal trait. These results are very low compared with the dairy breeding programs modeled in this study or to the gains commonly predicted in dairy cattle. Indeed, as previously mentioned, breeding programs for small ruminants, especially meat sheep, involve inherent factors that limit genetic gains (e.g., few animals per breeding unit, limited use of AI, low capacity of progeny testing) and also have less than optimal designs. As explained above, these designs should
Table 3. Annual genetic gain for meat (AGGb) and maternal (AGGm) traits for different scenarios of the meat breeding program

\begin{tabular}{lllllllll}
\hline \hline \multirow{2}{*}{$\begin{array}{l}\text { Selection scheme } \\
\text { scenario }^{1}\end{array}$} & \multicolumn{2}{c}{ Current $^{2}$} & & \multicolumn{2}{c}{ Optimized_AI $^{3}$} & & \multicolumn{2}{c}{ Optimized $^{4}$} \\
\cline { 2 - 3 } \cline { 7 - 8 } & AGGb & AGGm & & AGGb & AGGm & & AGGb & AGGm \\
\hline Class-PT-culling & 0.095 & 0.061 & & 0.121 & 0.087 & & 0.139 & 0.096 \\
Class-PT-index & 0.112 & 0.072 & & 0.126 & 0.094 & & 0.143 & 0.108 \\
Class-young & 0.113 & 0.046 & & 0.135 & 0.047 & & 0.140 & 0.043 \\
GS & 0.115 & 0.091 & & 0.143 & 0.102 & & 0.151 & 0.097 \\
GS-pheno & 0.146 & 0.093 & & 0.169 & 0.098 & & 0.173 & 0.095 \\
GS-PT-culling & 0.102 & 0.084 & & 0.117 & 0.089 & & 0.141 & 0.096 \\
GS-PT-index & 0.113 & 0.095 & & 0.131 & 0.115 & & 0.146 & 0.123 \\
GS-pheno-PT-culling & 0.108 & 0.097 & & 0.126 & 0.102 & & 0.130 & 0.120 \\
GS-pheno-PT-index & 0.121 & 0.093 & & 0.139 & 0.119 & & 0.151 & 0.126 \\
\hline
\end{tabular}

${ }^{1}$ Class-PT-culling: phenotypic selection and progeny testing with independent culling level selection, Class-PT-index: phenotypic selection and progeny testing with index selection, Class-young: phenotypic selection without progeny testing, GS: pure genomic selection, GS-pheno: combined genomic and a meat phenotype selection, GS-PT-culling: genomic selection and progeny testing with independent culling level selection, GS-PT-index: genomic selection and progeny testing with index selection, GS-pheno-PTculling: combined genomic and a meat phenotype selection and progeny testing with independent culling level selection, and GS-pheno-PT-index: combined genomic and a meat phenotype selection and progeny testing with index selection.

${ }^{2}$ Decisional variables are those used in current breeding programs except for genomic information

${ }^{3}$ Decisional variables were optimized but AI was limited to its current level of use in the breeding unit. Optimized_AI: the use of AI is not optimized.

${ }^{4}$ No restriction on AI.

${ }^{5}$ The Class-PT-culling was used as a reference scenario. There was no genetic correlation between meat and maternal traits. For genomic scenarios, the $r_{\mathrm{GBV}}$ was calculated using $\mathrm{Ne}=200$, a genome size of 27 Morgan, and nref $=2,000 . \mathrm{Ne}=$ effective population size; $r_{\mathrm{GBV}}=$ the genomic prediction accuracy; nref $=$ reference population size.

be optimized to guarantee a fair comparison of alternative schemes. Table 3 shows that optimizing designs (current to optimized) significantly increased genetic gain in all scenarios for both meat and maternal traits. The greatest increase was observed in the reference scenario, ClassPT-culling, where the genetic gain was increased by $57.4 \%$ for the meat trait and $46.3 \%$ for the maternal trait. Optimization of design led to an improvement of genetic

Table 4. Annual genetic gain for different scenarios of the Red Faced Manech (RFM) sheep and Alpine goat breeding programs

\begin{tabular}{|c|c|c|c|c|c|c|}
\hline \multirow{2}{*}{$\begin{array}{l}\text { Selection scheme } \\
\text { scenario }^{1}\end{array}$} & \multicolumn{3}{|c|}{ RFM } & \multicolumn{3}{|c|}{ Alpine } \\
\hline & Current $^{2}$ & Optimized_AI ${ }^{3}$ & Optimized $^{4}$ & Current $^{2}$ & Optimized_AI ${ }^{3}$ & Optimized $^{4}$ \\
\hline $\begin{array}{l}\text { Class-PT-index } \\
\text {. }\end{array}$ & 0.147 & 0.167 & 0.174 & 0.120 & 0.173 & 0.183 \\
\hline GS & 0.248 & 0.254 & 0.264 & 0.207 & 0.223 & 0.231 \\
\hline
\end{tabular}

\footnotetext{
${ }^{1}$ Class-PT-index: phenotypic selection based on progeny tests records and with index selection, GS-PT-index: genomic selection and progeny testing with index selection and GS: pure genomic selection.

${ }^{2}$ Decisional variables were those used in current breeding programs except for genomic information.

${ }^{3}$ Decisional variables were optimized but the AI was limited to its current level of use in the breeding unit. Optimized_AI: the use of AI is not optimized.

${ }^{4}$ No restriction on AI. The genomic prediction accuracy $\left(r_{\mathrm{GBV}}\right)$ was calculated based on $\mathrm{Ne}=200$, nref $=2,000$, and a genome size of $27 \mathrm{Morgan}$ for RFM and 30 Morgan for Alpine. $\mathrm{Ne}=$ effective population size; nref $=$ reference population size.
} 
gain in all meat-breeding scenarios of over $20 \%$ for the meat trait and $14 \%$ for the maternal trait, except in 2 scenarios where the increase for the maternal trait was of less than 7\% (i.e., GS and GS-pheno scenarios). It is also important to note that similar trends were observed by optimizing designs without modifying the rate of AI [Current to Optimized_AI (all decisional variables are optimized except the number of doses of AI); Table 3]. This suggests that genetic gain can be improved without increasing the amount of AI used in a breeding unit [i.e., by optimizing parameters such as the number of male selection candidates, male progeny tested, progeny group size, elite males, and technical weights of the selection index $\left.\left(\mathrm{w}_{\mathrm{b}}, \mathrm{w}_{\mathrm{m}}\right)\right]$.

The comparison of the genetic gains obtained with different scenarios using optimized parameters showed that including genomic information generally provided greater overall AGG. The combined genetic gain in both traits (AGGb + AGGm) was greater by approximately $14 \%$ for GS-pheno and GS-PT-index and 17\% for GS-phenoPT-index as compared with the reference scenario (ClassPT-culling). The increase was, however, of less than 7\% for the other scenarios. Similar trends were observed when comparing scenarios with limited AI, but the superiority of genomic schemes was slightly greater. For individual traits, increases were of up to $24.4 \%$ for the meat trait (ClassPT-culling vs. GS-pheno) and 31.2\% for the maternal trait (Class-PT-culling vs. GS-pheno-PT-index). However, the genetic gains were slightly reduced for the maternal trait with the "GS-pheno" scenario and for the meat trait with the "GS-pheno-PT-culling" scenario. When the size of the reference population was over 2,000 individuals, the trait and combined genetic gain of all genomic scenarios were superior to conventional scenarios (Fig. 2). Using the same information sources, the combined genetic gain was greater when index selection methods were used than with independent culling level methods.

\section{Dairy Breeding Programs}

Results for the 2 dairy breeding programs are shown in Table 4. The selection plan for the RFM sheep breed as it is designed and used today is expected to give a predicted annual genetic gain of $0.147 \sigma_{a}$ (for a milk trait of $h^{2}=0.30$ and a repeatability of 0.50 ). Comparisons based on optimized schemes showed that the genetic gain was significantly increased by including genomewide information: up to $26.9 \%$ for the GS-PTindex scenario where genomic information was used to preselect candidates for progeny testing and $51.7 \%$ for the pure GS scenario where selection of elite rams was exclusively based on genomic information and progeny testing avoided. The results for the breeding program of "Alpine" dairy goats showed a similar trend, with use (a)

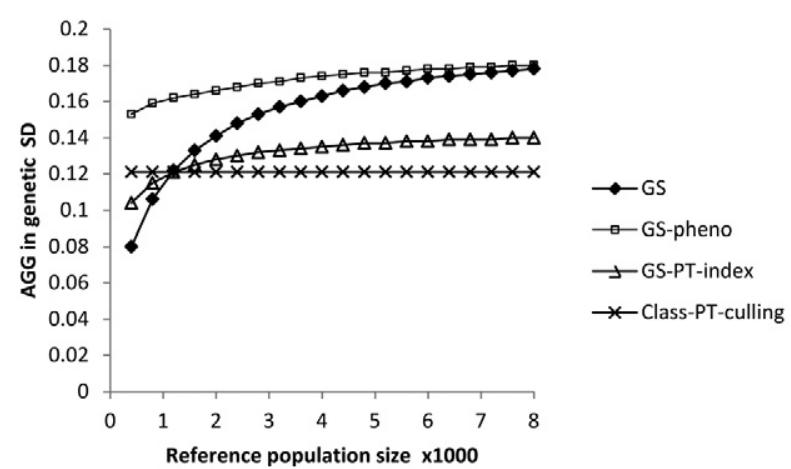

(b)

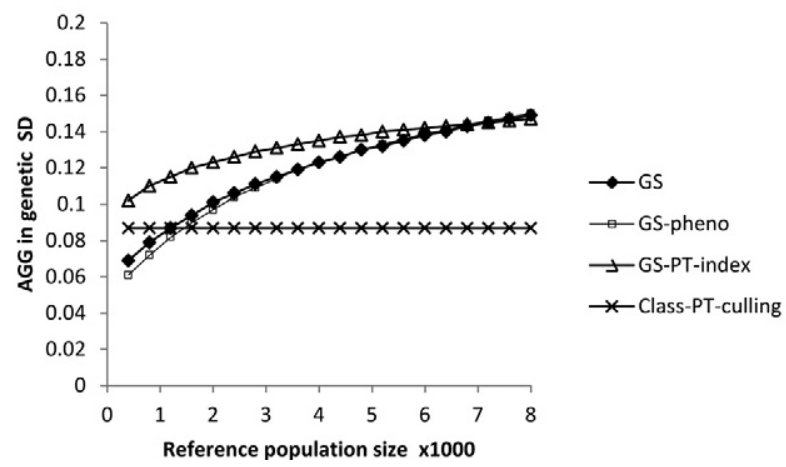

Figure 2. Effect of reference population size on the annual genetic gain (AGG) of the meat breeding program. (a) Gains on meat trait and (b) gains on maternal trait. Different lines indicate different scenarios at the optimized variables: GS $=$ pure genomic selection, GS-pheno $=$ combined genomic and a meat phenotype selection, GS-PT-index $=$ genomic selection and progeny testing, and Class-PT-culling $=$ conventional selection. For genomic scenarios, the genomic prediction accuracy $\left(r_{\mathrm{GBV}}\right)$ was calculated considering $\mathrm{Ne}=200$ and a genome size of 27 Morgan.

of genomic information increasing the genetic gain by $18.6 \%$ for the GS-PT-index scheme and $26.2 \%$ for the pure GS scheme (Table 4). Trends were similar when scenarios were compared with limited AI. Optimizing the designs increased the genetic gain for all scenarios and both breeds. The increase was greatest for the conventional scenario where AGG increased by $18.4 \%$ for RFM sheep and by $52.5 \%$ for Alpine goats (i.e., from $0.147 \sigma_{a}$ to $0.174 \sigma_{a}$ for RFM sheep and from $0.120 \sigma_{a}$ to $0.183 \sigma_{a}$ for Alpine goats). These theoretical results are relatively close to the realized genetic gains in these breeding programs. In the RFM breeding program, the AGG of milk yield was calculated at $4.33 \mathrm{~kg} / \mathrm{yr}$, which is equivalent to $0.173 \sigma_{a}$ (Astruc et al., 2002). In the Alpine breeding program, the AGG of milk yield was reported to be $8.63 \mathrm{~kg} / \mathrm{yr}$, which is equivalent to 0.122 $\sigma_{a}$ (Montaldo and Manfredi, 2002). 
(a)

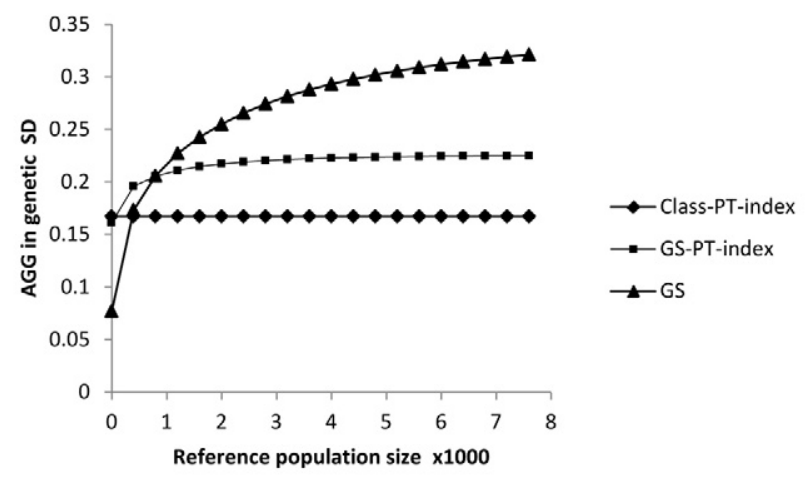

(b)

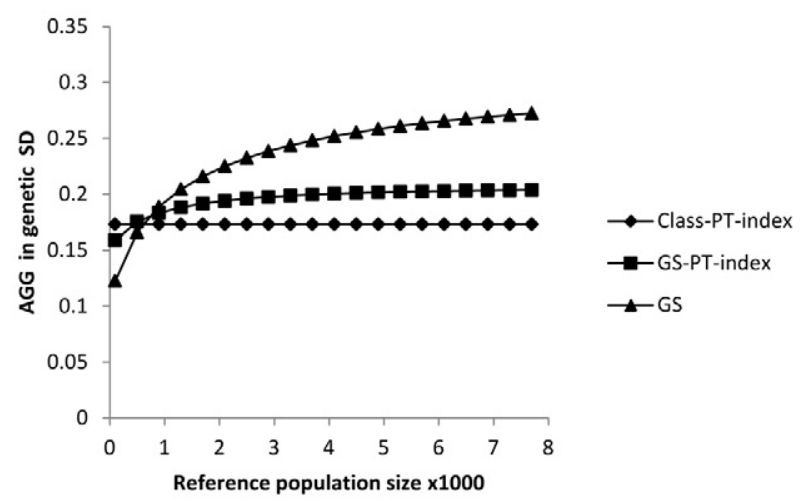

Figure 3. Effect of reference population size on the annual genetic gain (AGG) of dairy breeding programs. (a) Red Faced Manech (RFM) sheep breeding program and (b) Alpine breeding program. Different lines indicate different scenarios: Class-PT-index $=$ conventional selection, GS-PT-index $=$ genomic selection and progeny testing, and GS = pure genomic selection. Genomic prediction accuracy, $r_{\mathrm{GBV}}$, was calculated using $\mathrm{Ne}=200$ and a genome size of 27 Morgan for RFM and 30 Morgan for Alpine breeds.

\section{Effect of Reference Population Size}

The effects of reference population size on the annual genetic gain of the meat and dairy breeding programs are presented in Fig. 2 and 3, respectively. As expected, the results show that the genetic response increases with the size of the reference population in all scenarios in which genomic information was included. In all breeds, the change in genetic gain obtained by increasing the size of the reference population was substantially larger for the scenario where selection depended only on genomic information (i.e., the GS scenario). In all scenarios increasing the reference population size resulted in a diminishing return increase of genetic gain; this was particularly the case for scenarios using both phenotypic and genomic information (e.g., GS-pheno, GS-PTindex scenarios). At the reference population size of 1,000 individuals in dairy and 2,000 individuals in meat breeding programs, genomic scenarios outperformed conventional scenarios.

\section{Effects of Correlation between Meat and Maternal Traits}

The results presented in Table 5 show that genetic correlations between traits greatly impact the genetic gain for all scenarios. For both traits the AGG changed consistently along with the genetic correlation, being the most strongly impacted maternal traits. This is usually due to correlated response that could be greater for a trait with less informative information sources (e.g., low heritability and/or less information included in index). When comparing the relative gain of different scenarios (Table 5) to that of the reference, a high sensitivity to correlations was found for all scenarios. A negative genetic correlation had the largest effect on the scenarios ranking, being the most affected the scenario in which an early meat phenotype was combined with genomic information was the most affected (GS-pheno).

\section{Effects of Economic Weights on Genetic Gain}

To test the stability of the results against economic weights, we analyzed the effect of economic weights in the objective function on the total genetic gain of the Mouton Ile de France breed. Results in Table 6 show that changes to these weighting parameters affected the total genetic gain but that the rank and relative differences between alternative breeding programs were not significantly changed.

\section{DISCUSSION}

The objective of this study was to predict the potential benefits of genomic selection on the genetic gain that can be expected in breeding programs for small ruminants. Selection targeted to improve 2 traits in meat sheep breed and a single trait in both dairy sheep and goat breeds. Comparisons of alternative conventional and genomic selection strategies were based on the AGG. For genomic schemes, a mediumsized reference population was considered to calculate genomic prediction accuracies. The effects of reference population size on the genetic gain were also evaluated. All selection scenarios were optimized to ensure comparisons were fair.

\section{The Selection Model}

The model was developed to be flexible to include the various components of the selection strategies as observed in actual small ruminant breeding programs. It took into account overlapping generations and included single- and 2-stage selections for males and selection of females across age classes with a unique truncation point across multinormal distributions of their breeding values. 
Table 5. Annual genetic gain for meat (AGGb) and maternal (AGGm) traits and relative gain (RG) on combined traits $(\%)$ compared with the reference scheme (Class-PT-culling) for genetic correlations $\left(\rho_{m p}\right)=0.0$ or -0.2 or 0.2$)$ and different breeding scenarios

\begin{tabular}{|c|c|c|c|c|c|c|c|c|c|}
\hline \multirow{2}{*}{$\begin{array}{l}\text { Selection scheme } \\
\text { scenario }^{1}\end{array}$} & \multicolumn{3}{|c|}{$\rho_{m b}=-0.20$} & \multicolumn{3}{|c|}{$\rho_{m b}=0.00$} & \multicolumn{3}{|c|}{$\rho_{m b}=0.20$} \\
\hline & $\mathrm{AGGb}$ & AGGm & RG (\%) & $\mathrm{AGGb}$ & AGGm & RG (\%) & $\mathrm{AGGb}$ & AGGm & RG (\%) \\
\hline Class-PT-culling & 0.106 & 0.066 & 100 & 0.121 & 0.087 & 100 & 0.137 & 0.102 & 100 \\
\hline Class-young & 0.124 & 0.019 & 83 & 0.135 & 0.047 & 88 & 0.149 & 0.072 & 92 \\
\hline GS & 0.123 & 0.045 & 98 & 0.143 & 0.102 & 118 & 0.176 & 0.139 & 132 \\
\hline GS-pheno & 0.113 & 0.025 & 80 & 0.169 & 0.098 & 128 & 0.203 & 0.221 & 177 \\
\hline GS-pheno-PT-culling & 0.089 & 0.057 & 85 & 0.126 & 0.102 & 110 & 0.15 & 0.168 & 133 \\
\hline GS-pheno-PT-index & 0.114 & 0.094 & 121 & 0.139 & 0.119 & 124 & 0.162 & 0.139 & 126 \\
\hline
\end{tabular}

${ }^{1}$ Scenarios were compared with optimized decisional variables, but limited AI. The genomic prediction accuracy $\left(r_{\mathrm{GBV}}\right)$ was calculated considering effective population size $(\mathrm{Ne})=200$, a genome size of 27 Morgan, and reference population size (nref) $=2,000$. Class-PT-culling: phenotypic selection and progeny testing with independent culling level selection, Class-PT-index: phenotypic selection and progeny testing with index selection, Class-young: phenotypic selection without progeny testing, GS: pure genomic selection, GS-pheno: combined genomic and a meat phenotype selection, GS-PT-culling: genomic selection and progeny testing with independent culling level selection, GS-PT-index: genomic selection and progeny testing with index selection, GS-pheno-PT-culling: combined genomic and a meat phenotype selection and progeny testing with independent culling level selection, and GS-pheno-PT-index: combined genomic and a meat phenotype selection and progeny testing with index selection.

Therefore, genetic variance changes after each selection step and generation, and this affects genetic response. In all conventional and genomic scenarios, the Bulmer effect was accounted for to avoid incorrect ranking of selection strategies. Indeed, selection intensities and accuracies varied among scenarios and the Bulmer effect was estimated as a function of selection accuracy and intensity (Bulmer, 1971). The GBV prediction accuracies $\left(r_{\mathrm{GBV}}\right)$ used here were calculated as suggested by Daetwyler et al. (2008) and Goddard (2009). Using these methods, $r_{\mathrm{GBV}}$ is greatest when $\mathrm{Ne}$ and genome size are small and the reference population size is big. Published studies on genetic diversity in sheep (Huby et al., 2003; Palhiere et al., 2008; Garcia-Gamez et al., 2012) and goat (Araújo et al., 2006; Ribeiro et al., 2012) breeds have shown that small ruminant populations are heterogeneous and display high effective population sizes compared with most selected cattle breeds. This is positive for the long term selection response but, with the methods used here, negatively affects the genomic prediction accuracies. Also, these methods (Daetwyler et al., 2008; Goddard, 2009) assume the reference and validation populations are not closely related, which could underestimate the genomic prediction accuracy. Indeed, genomic evaluation studies have shown that GBV are more accurate when selection candidates are closely related to the reference population (Habier et al., 2007, 2010).

The optimization procedures used here maximized the AGG by optimizing, within certain limits, the number of young male selection candidates, tested males, progeny group size, use of AI, numbers of selected males (elites and NS), and relative weights in the breeding goal.
The results obtained here confirm the need to optimize designs; as compared with the expected level for current practices, AGG was greatly increased for all scenarios by optimization. The greatest increases were recorded for conventional selection methods, where AGG was increased by $50.6 \%$ in meat sheep, $18.4 \%$ in dairy sheep, and $52.5 \%$ in dairy goats. Indeed, in meat sheep the increase of AGG obtained by optimization was nearly equivalent to the increase that the use of genomic information can offer with current decisional variables. Our results highlight i)

Table 6. Sensitivity of the objective function to economic weights of meat and maternal traits in the overall genetic gain

\begin{tabular}{lccc}
\hline \hline Selection scheme & \multicolumn{3}{c}{ Superiority to reference (\%) } \\
\cline { 2 - 4 } scenario $^{1}$ & $\alpha \mathrm{m} / \mathrm{\alpha b}^{2}=1.5 / 0.5$ & $\alpha \mathrm{m} / \alpha \mathrm{b}=1 / 1$ & $\alpha \mathrm{m} / \alpha \mathrm{b}=0.5 / 1.5$ \\
\hline GS-PT-culling & -10.63 & -0.96 & 2.00 \\
Class-PT-culling $^{3}$ & 0.00 & 0.00 & 0.00 \\
Class-PT-index & -3.38 & 5.77 & 6.00 \\
GS-pheno-PT-culling & 5.31 & 9.62 & 9.00 \\
GS & 8.21 & 17.79 & 15.00 \\
GS-PT-index & 13.53 & 18.27 & 19.50 \\
GS-pheno-PT-index & 16.91 & 24.04 & 21.00 \\
GS-pheno & 17.39 & 28.37 & 27.50 \\
\hline
\end{tabular}

${ }^{1}$ GS-PT-culling: genomic selection and progeny testing with independent culling level selection, Class-PT-culling: phenotypic selection and progeny testing with independent culling level selection, Class-PT-index: phenotypic selection and progeny testing with index selection, GS-pheno-PT-culling: combined genomic and a meat phenotype selection and progeny testing with independent culling level selection, GS: pure genomic selection, GSPT-index: genomic selection and progeny testing with index selection, GSpheno-PT-index: combined genomic and a meat phenotype selection and progeny testing with index selection, and GS-pheno: combined genomic and a meat phenotype selection.

${ }^{2}$ The $\alpha \mathrm{b}$ and $\alpha \mathrm{m}$ are economic weights of meat and maternal traits, respectively, considered in the objective function.

${ }^{3}$ The reference scenario with which the relative change was compared. 
the suboptimality of current breeding programs and ii) the importance of using meat phenotypes recorded at an early age in the selection criteria. In principle, the model developed herein could be extended to include selection in finite populations, rate of inbreeding, and the economic aspects of breeding strategies.

\section{Genetic Gain}

In the meat breeding program, where 2 traits were improved, genomic information increased AGG by 1 to $17.9 \%$ depending on the scenario. Genomic scenarios were most efficient when a meat phenotype was combined with genomic information to select or preselect elite sires, except when selection was performed using independent culling levels. When optimized designs were compared, the purely GS was only 5.5\% superior to conventional selection. This demonstrates the importance of a phenotype, in situations where it is recorded at an early age and when the reference population is small (nref $=2,000$ ). Our results are consistent with the decreased performance of independent culling methods compared with index (Hazel and Lush, 1942). For all scenarios of the meat breeding program, genomic superiority was less than that reported in dairy cattle studies (e.g., Schaeffer, 2006; Konig and Swalve, 2009; Pryce et al., 2010) mainly due to some limitations in population parameters such as few individuals in breeding units, low use of AI, and small progeny testing capacity, which negatively affect selection intensity and accuracy.

In dairy sheep and goat breeding programs, when parameters were optimized, the benefits of including genomic information reached $51.7 \%$ for dairy sheep and $26.2 \%$ for dairy goats. The superiority of genomic schemes was mainly due to low generation interval and use of genomic information to preselect progeny test males, a step that is not available in conventional selection. The increase in AGG was greatest when progeny testing was eliminated, which means the benefits of short generation interval are greater than the losses in low accuracy. This is in line with the results reported for dairy cattle where progeny testing was eliminated (e.g., Schaeffer, 2006; Konig and Swalve, 2009; Pryce et al., 2010; Egger-Danner et al., 2012). The $51.7 \%$ increase in AGG for RFM sheep was close to the genomic benefits reported in these dairy cattle studies but not as high as results reported by Schaeffer (2006). Indeed, unlike in our study, Schaeffer (2006) considered genomic information in the female to male selection path, greater reduction in generation interval, and greater genomic accuracy. The $r_{\mathrm{GBV}}$ corresponding to nref $=2,000$ used here was relatively small compared with that used in dairy cattle genomic evaluation studies, either by simulation (Meuwissen et al., 2001) or with real data (VanRaden et al., 2009). It could, however, be realistic in small ruminants (Duchemin et al., 2012).

When $r_{\mathrm{GBV}}$ was increased via the increase of individuals in the reference population, genomic superiority clearly increased in all scenarios. Also, the importance of phenotypic information and preselection for progeny testing decreased when the size of the reference population increased.

The genetic gain for meat and maternal traits was very sensitive to their genetic correlation, especially for the maternal trait. This could be due to disparity in heritabilies between the 2 traits. Indeed, a study on the efficiency of genomic selection on net merit (Togashi et al., 2011) reported that the efficiency was affected by heritability, correlations, and genetic variance ratio between traits. This could be the reason why the choice of best scenario was affected when the maternal trait had very low heritability compared with the meat trait in the present study. Whether selection is conventional or genomic, our results show the importance of having accurate genetic parameter estimates for multitrait selection.

In this study, only male selection candidates were genotyped because we assume, due to the cost of genotyping and the value of reproducers, that the first attempts to use genomic selection in small ruminants will prioritize males. Indeed, a recent study describing a genotyping strategy for genomic selection by Henryon et al. (2012) found that only genotyping male candidates brings most of the benefits expected from genomic selection.

To conclude, AGG in all scenarios was increased by optimization of decisional variables and including genomic information. However, these benefits remain on the technical aspects. So further studies should evaluate the monetary inputs and outputs of these selection strategies.

\section{LITERATURE CITED}

Araújo, A. M. d., S. E. F. Guimarães, T. M. M. Machado, P. S. Lopes, C. S. Pereira, F. L. R. da Silva, M. T. Rodrigues, V. de S. Columbiano, and C. G. da Fonseca. 2006. Genetic diversity between herds of Alpine and Saanen dairy goats and the naturalized Brazilian Moxotó breed. Genet. Mol. Biol. 29:67-74.

Astruc, J. M., F. Barillet, A. Barbat, V. Clement, and D. Boichard. 2002. Genetic evaluation of dairy sheep in France. In: 7th World Congr. Genet. Appl. Livest. Prod., Montpellier, France. p. 231-234.

Bichard, M., A. H. R. Pease, P. H. Swales, and K. Özkütük. 1973. Selection in a population with overlapping generations. Anim. Sci. 17:215-227.

Boichard, D., F. Guillaume, A. Baur, P. Croiseau, M. N. Rossignol, M. Y. Boscher, T. Druet, L. Genestout, J. J. Colleau, L. Journaux, V. Ducrocq, and S. Fritz. 2012. Genomic selection in French dairy cattle. Anim. Prod. Sci. 52:115-120. 
Buch, L. H., M. K. Sorensen, P. Berg, L. D. Pedersen, and A. C. Sorensen. 2012. Genomic selection strategies in dairy cattle: Strong positive interaction between use of genotypic information and intensive use of young bulls on genetic gain. J. Anim. Breed. Genet. 129:138-151.

Bulmer, M. G. 1971. The effect of selection on genetic variability. Am. Nat. 105:201-211.

Daetwyler, H. D., K. E. Kemper, J. H. van der Werf, and B. J. Hayes. 2012. Components of the accuracy of genomic prediction in a multi-breed sheep population. J. Anim. Sci. (in press). doi:10.2527/jas.2011-4557

Daetwyler, H. D., B. Villanueva, and J. A. Woolliams. 2008. Accuracy of predicting the genetic risk of disease using a genome-wide approach. PLoS ONE 3:E3395.

Dekkers, J. C. 2007. Prediction of response to marker-assisted and genomic selection using selection index theory. J. Anim. Breed. Genet. 124:331-341.

Duchemin, S. I., C. Colombani, A. Legarra, G. Baloche, H. Larroque, J. M. Astruc, F. Barillet, C. Robert-Granié, and E. Manfredi. 2012. Genomic selection in the French Lacaune dairy sheep breed. J. Dairy Sci. 95:2723-2733.

Ducrocq, V., and J. J. Colleau. 1989. Optimum truncation points for independent culling level selection on a multivariate normal distribution, with an application to dairy cattle selection. Genet. Sel. Evol. 21:185-198.

Egger-Danner, C., A. Willam, C. Fuerst, H. Schwarzenbacher, and B. Fuerst-Waltl. 2012. Hot topic: Effect of breeding strategies using genomic information on fitness and health. J. Dairy Sci. 95:4600-4609.

Elsen, J. M., and J. C. Mocquot. 1976. Optimisation du renouvellement des femelles dans les troupeaux laitiers soumis au croisement terminal. (In French.) Genet. Sel. Evol. 8:1-14.

Garcia-Gamez, E., G. Sahana, B. Gutierrez-Gil, and J. J. Arranz. 2012. Linkage disequilibrium and inbreeding estimation in Spanish Churra sheep. BMC Genet. 13:43.

Goddard, M. 2009. Genomic selection: Prediction of accuracy and maximisation of long term response. Genetica 136:245-257.

Haberland, A. M., U. König von Borstel, H. Simianer, and S. König. 2012. Integration of genomic information into sport horse breeding programs for optimization of accuracy of selection. Animal 6:1369-1376.

Habier, D., R. L. Fernando, and J. C. Dekkers. 2007. The impact of genetic relationship information on genome-assisted breeding values. Genetics 177:2389-2397.

Habier, D., J. Tetens, F.-R. Seefried, P. Lichtner, and G. Thaller. 2010. The impact of genetic relationship information on genomic breeding values in German Holstein cattle. Genet. Sel. Evol. 42:5.

Hayes, B. J., P. J. Bowman, A. J. Chamberlain, and M. E. Goddard. 2009. Invited review: Genomic selection in dairy cattle: Progress and challenges. J. Dairy Sci. 92:433-443.

Hazel, L. N. 1943. The genetic basis for constructing selection indexes. Genetics 28:476-490.

Hazel, L. N., and J. L. Lush. 1942. The efficiency of three methods of selection. J. Hered. 33:393-399.

Henryon, M., P. Berg, T. Ostersen, B. Nielsen, and A. C. Sorensen. 2012. Most of the benefits from genomic selection can be realized by genotyping a small proportion of available selection candidates. J. Anim. Sci. 90:4681-4689.
Huby, M., L. Griffon, S. Moureaux, H. De Rochambeau, C. DanchinBurge, and E. Verrier. 2003. Genetic variability of six French meat sheep breeds in relation to their genetic management. Genet. Sel. Evol. 35:637-655.

Konig, S., and H. H. Swalve. 2009. Application of selection index calculations to determine selection strategies in genomic breeding programs. J. Dairy Sci. 92:5292-5303.

Lund, M. S., A. P. Roos, A. G. Vries, T. Druet, V. Ducrocq, S. Fritz, F. Guillaume, B. Guldbrandtsen, Z. Liu, R. Reents, C. Schrooten, F. Seefried, and G. Su. 2011. A common reference population from four European Holstein populations increases reliability of genomic predictions. Genet. Sel. Evol. 43:43.

Meuwissen, T. H., B. J. Hayes, and M. E. Goddard. 2001. Prediction of total genetic value using genome-wide dense marker maps. Genetics 157:1819-1829.

Montaldo, H. H., and E. Manfredi. 2002. Organisation of selection programmes for dairy goats. Commun. No. 01-35. In: Proc. 7th World Congr. Genet. Appl. Livest. Prod., Montpellier, France.

Palhiere, I., M. Brochard, K. Moazami-Goudarzi, D. Laloeë, Y. Amigues, B. Bed'hom, E. Neuts, C. Leymarie, T. Pantano, E. P. Cribiu, B. Bibé, and E. Verrier. 2008. Impact of strong selection for the PrP major gene on genetic variability of four French sheep breeds. Genet. Sel. Evol. 40:663-680.

Pimentel, E. C., and S. Konig. 2012. Genomic selection for the improvement of meat quality in beef. J. Anim. Sci. 90:34183426.

Pryce, J. E., M. E. Goddard, H. W. Raadsma, and B. J. Hayes. 2010. Deterministic models of breeding scheme designs that incorporate genomic selection. J. Dairy Sci. 93:5455-5466.

Ribeiro, M. N., C. Bruno-de-Sousa, A. Martinez-Martinez, C. Ginja, M. P. Menezes, E. C. Pimenta-Filho, J. V. Delgado, and L. T. Gama. 2012. Drift across the Atlantic: Genetic differentiation and population structure in Brazilian and Portuguese native goat breeds. J. Anim. Breed. Genet. 129:79-87.

Safari, E., N. M. Fogarty, A. R. Gilmour, K. D. Atkins, S. I. Mortimer, A. A. Swan, F. D. Brien, J. C. Greeff, and J. H. van der Werf. 2007. Genetic correlations among and between wool, growth and reproduction traits in Merino sheep. J. Anim. Breed. Genet. 124:65-72.

Schaeffer, L. R. 2006. Strategy for applying genome-wide selection in dairy cattle. J. Anim. Breed. Genet. 123:218-223.

Togashi, K., C. Y. Lin, and T. Yamazaki. 2011. The efficiency of genome-wide selection for genetic improvement of net merit. J. Anim. Sci. 89:2972-2980.

VanRaden, P. M., C. P. Van Tassell, G. R. Wiggans, T. S. Sonstegard, R. D. Schnabel, J. F. Taylor, and F. S. Schenkel. 2009. Invited review: Reliability of genomic predictions for North American Holstein bulls. J. Dairy Sci. 92:16-24.

\section{APPENDIX 1.}

Relationships between parameters and decision variables and contributions of each reproduction category to male and female progenies. Appendix Table 1 of this appendix contains simple equations that associate the parameters and decisional variables given in Table 2 of this article. Appendix Table 2 shows how parent contributions were calculated. 
Appendix Table 1. Relationships among the various parameters and variables used in the model

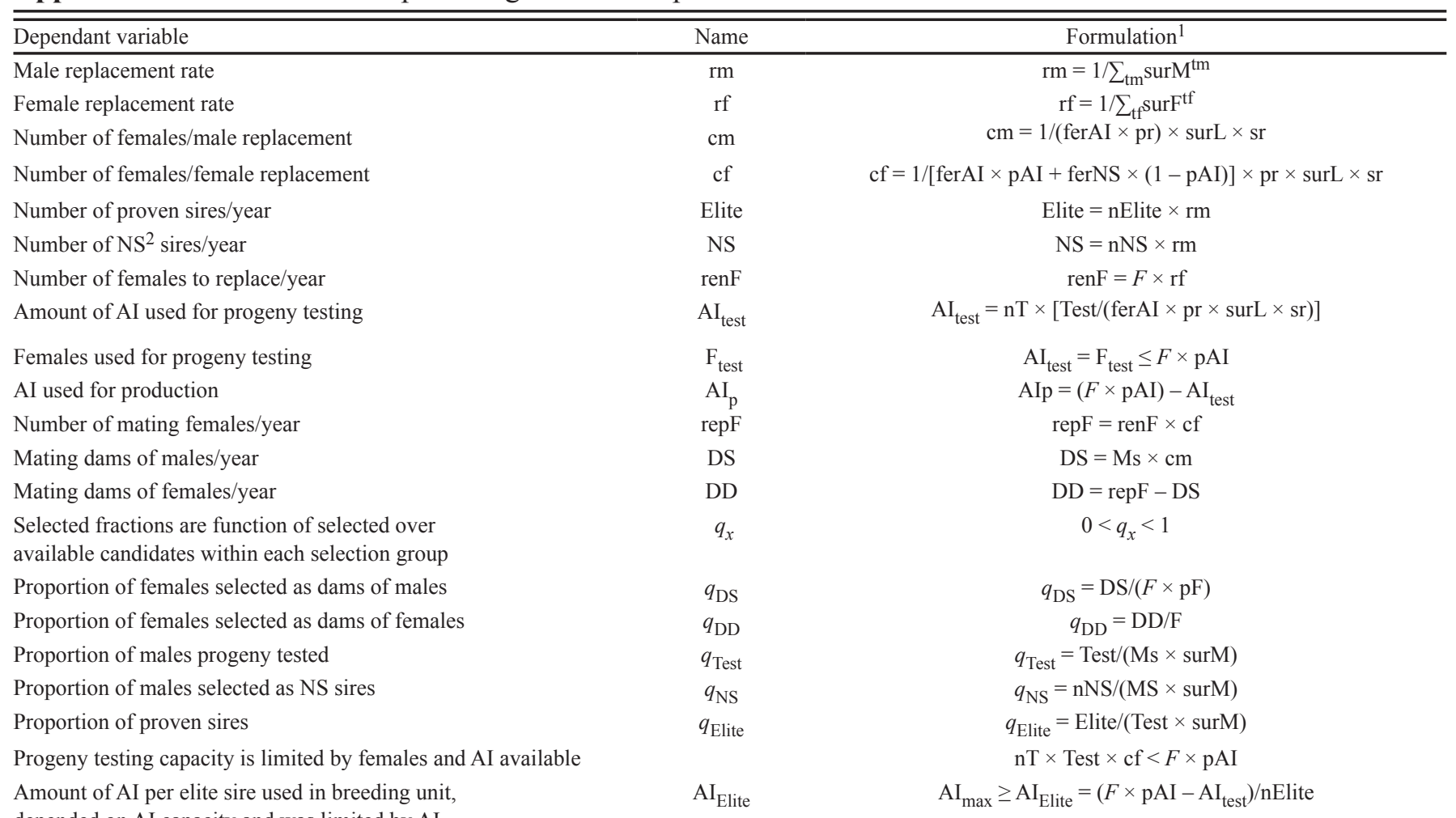
depended on AI capacity and was limited by $\mathrm{AI}_{\max }$

${ }^{1} \mathrm{tm}$ and $\mathrm{tf}=$ time units males and females are kept in service, respectively; surM and surF = stayability of males and females, respectively, in breeding unit; surL = survival rate at maturity; ferAI and ferNS = fertility with $\mathrm{AI}$ and with natural service, respectively; $\mathrm{pr}=$ prolificacy; $\mathrm{sr}=\mathrm{sex}$ ratio; $\mathrm{pAI}=\mathrm{quantity}$ of $\mathrm{AI}$ as percent of recorded females; $\mathrm{nElite}=$ total elite sires in breeding unit; $\mathrm{nNS}=$ total number of natural service sires in breeding unit; $F$ : number of recorded females; $\mathrm{nT}=$ number of progeny/test sire; Test = males to be progeny tested/year; $\mathrm{Ms}=$ male selection candidates; $\mathrm{pF}=$ percent of females qualified to be dams of male replacements; $\mathrm{AI}_{\max }=$ maximum number of AI doses per elite sire in breeding unit.

${ }^{2} \mathrm{NS}=$ Natural Service.

Appendix Table 2. Proportions contributed by each parent category ${ }^{1}$

\begin{tabular}{|c|c|}
\hline Description $^{2}$ & Formulation $^{3}$ \\
\hline Contribution of each Elite group to male-male selection path & $c_{\text {Elite }, \mathrm{MM}}=\left(\mathrm{AI}_{\text {Elite }} \times \mathrm{nElite}\right) /(\mathrm{MS} \times \mathrm{cm}) ; 0 \leq c_{\text {Elite }, \mathrm{MM}} \leq 1$ \\
\hline Contribution of each Elite group to male-female selection path & $c_{\text {Elite, } \mathrm{MF}}=\left(\mathrm{AI}_{\text {Elite }} \times \mathrm{nElite}\right) /(\mathrm{renF} \times \mathrm{cf}) ; 0 \leq c_{\text {Elite,MF }} \leq 1$ \\
\hline Contribution of test sires to MM selection path & $c_{\text {test,MM }}=($ Test $\times \mathrm{nT}) /(\mathrm{Ms} \times \mathrm{cm}) ; 0 \leq c_{\text {test }, \mathrm{MM}} \leq\left(1-c_{\text {Elite,MM }}\right)$ \\
\hline Contribution of test sires to MF selection path & $c_{\text {test }, \mathrm{MF}}=($ Test $\times \mathrm{nT}) /(\mathrm{renF} \times \mathrm{cf}) ; 0 \leq c_{\text {test }, \mathrm{MF}} \leq 1$ \\
\hline Contribution of NS sires to male progeny & $c_{\mathrm{NS}, \mathrm{MM}}=1-\left(c_{\text {Elite,MM }}+c_{\text {test,MM }}\right) ; 0 \leq c_{\mathrm{NS}, \mathrm{MM}} \leq 1$ \\
\hline Contribution of NS sires to female progeny & $c_{\mathrm{NS}, \mathrm{MF}}=1-\left(c_{\text {Elite, } \mathrm{MF}}+c_{\text {test, } \mathrm{MF}}\right) ; 0 \leq c_{\mathrm{NS}, \mathrm{MF}} \leq 1$ \\
\hline Contribution of DS to female-male selection path & $c_{\mathrm{DS}, \mathrm{FM}}=\mathrm{DS} /(\mathrm{Ms} \times \mathrm{cm}) ; 0 \leq c_{\mathrm{DS}, \mathrm{FM}} \leq 1$ \\
\hline Contribution of DS to female-female selection path & $c_{\mathrm{DS}, \mathrm{FF}}=\mathrm{DS} /(\mathrm{renF} \times \mathrm{cf}) ; 0 \leq c_{\mathrm{DS}, \mathrm{FF}} \leq 1$ \\
\hline Contribution of DD to FM selection path & $c_{\mathrm{DD}, \mathrm{FM}}=\mathrm{DD} /(\operatorname{renF} \times \mathrm{cf}) ; 0 \leq c_{\mathrm{DD}, \mathrm{FM}} \leq\left(1-c_{\mathrm{DS}, \mathrm{FM}}\right)$ \\
\hline Contribution of DD to females & $c_{\mathrm{DD}, \mathrm{FF}}=\mathrm{DD} /(\mathrm{renF} \times \mathrm{cf}) ; 0 \leq c_{\mathrm{DD}, \mathrm{FF}} \leq\left(1-c_{\mathrm{DS}, \mathrm{FF}}\right)$ \\
\hline
\end{tabular}

Total contribution within selection path

$\sum c_{s p p}=1$; summation includes all parent categories contributing to the selection path

\footnotetext{
${ }^{1}$ The contribution $\left(c_{s l p}\right)$ of any selected parents of sex $s$ and genetic level $l$ to a corresponding selection path $p$ depends on their reproductive capacity and is limited by the contributions of other parent categories of the same sex but of superior genetic level.

${ }^{2}$ Elite $=$ best males of genetic level;DS and DD = first and second best female categories on genetic level; MM, MF, FM and FF for males to males, males to females, females to males and females to females selection paths, respectively.

${ }^{3} \mathrm{AI}_{\text {Elite }}=$ amount of AI per elite sire used in breeding unit; $\mathrm{nElite}=$ total number of elite sires in breeding unit; $\mathrm{Ms}=$ male selection candidates; $\mathrm{cm}=$ number of females $/$ male replacement; renF $=$ number of females to replace/year; $\mathrm{cf}=$ number of females/female replacement; $\mathrm{Test}=$ males to be progeny tested/year; $\mathrm{nT}=$ number of progeny/test sire .
} 